\title{
Gender and number in the nominal domain: An introduction*
}

\author{
Boban Arsenijević \\ Karl-Franzens-Universität Graz \\ boban.arsenijevic@uni-graz.at \\ Olga Borik \\ Universidad Nacional de Educación a Distancia (UNED) \\ oborik@flog.uned.es
}

\begin{abstract}
In this introduction, we provide a general overview of the properties of gender and number, two nominal grammatical categories that this special issue is devoted to. Grammatical gender and number have been studied from a variety of theoretical viewpoints and still there is no commonly established and well-defined view on the nature of the two categories. The term ' $g e n d e r$ ' is used for a range of grammatical phenomena, including noun-classification into corresponding inflection classes and syntactically conditioned rules of agreement and concord. Like grammatical gender, grammatical number can be realized through inflection on the noun and/or through the agreement that it triggers on other items. However, unlike grammatical gender, grammatical number has stable, straightforward and systematic interpretive effects, related to the quantity of the predicate denoted by the noun, and hence also of the referent when the nominal expression is referential. Number and gender are core features of nouns and make up or participate in some of the hallmark properties of natural language.
\end{abstract}

Keywords: noun; gender; number

\section{Resum. Gènere i nombre en el domini nominal: una introducció}

En aquesta introducció, fem un repàs general de les propietats del gènere i del nombre, les dues categories nominals de què s'ocupa aquest volum monogràfic. L'estudi del gènere i del nombre gramaticals s'ha abordat des de diverses perspectives teòriques i encara no hi ha una visió generalment acceptada $\mathrm{i}$ ben definida de la naturalesa d'aquestes dues categories. El terme gènere s'aplica a un ventall de fenòmens gramaticals que inclouen la classificació dels noms en classes flexives i les regles sintàctiques de concordança i acord. Com passa amb el gènere gramatical, el nombre gramatical es pot realitzar mitjançant la flexió del nom i/o la concordança que força en altres elements. No obstant això, a diferència del gènere gramatical, té efectes interpretatius

* We are very grateful to all the contributors for having accepted to collaborate with us, and the anonymous reviewers who participated in the peer-review process and whose time, commitment and comments have been highly appreciated both by the authors and by the editors of this volume. Last but not least, we thank the editorial board of CatJL for giving us the opportunity to edit this volume and for their support and patience in the process. 
estables, clars i sistemàtics, relacionats amb la quantitat del predicat que denota el nom, i, per tant, també del referent quan l'expressió nominal és referencial. El nombre i el gènere són trets fonamentals els noms i constitueixen algunes de les propietats definitòries del llenguatge natural o hi contribueixen.

Paraules clau: nom; gènere; nombre

\section{Table of Contents}
1. Introduction
4. The collection
2. The grammatical gender
References
3. The grammatical number

\section{Introduction}

We cannot begin this text by saying that nominal expressions are a lesser-studied domain of language, one that has not received the attention that it deserves. Nouns are a core lexical category: if a language has any lexical categories - nouns are among them (Sasse 2001, a.o.), they are the default means of establishing reference, they have been argued to be the only category that undergoes transfer from one language to another (Moravcsik 1975), they are typically the lexical category with the greatest number of members (e.g. Hudson 1994), they are ontologically unrestricted: unlike verbs or adjectives, they can denote individuals, events, properties, degrees (Arsenijević 2020). A vast amount of research has been conducted and published about the grammatical properties of nominal expressions. Still, some of the most important and most fundamental questions about the grammatical behavior of nouns and nominal expressions remain unanswered, so it would be fair to say that the more nouns and nominal phrases are investigated, the more intriguing and fascinating they become.

This issue is devoted to two of the most well-known grammatical categories of nouns: gender and number. Grammatical gender and number have been studied from a variety of theoretical viewpoints and still there is no commonly established and well-defined view on the nature of the two categories. Grammatical gender is a widespread category in nominal systems of various languages and can be found in a variety of typologically unrelated languages, starting from a well described Indo-European family to many languages of New Guinea (Corbett, 1991). One of the definitions of the category was proposed by Hockett (1958: 231): "Genders are classes of nouns reflected in the behavior of associated words." This definition underlines one of the basic facts about gender: it is a category that, to a large extent, determines nominal agreement properties and groups nouns into agreement classes and therefore can be safely considered a cross-boundary category with repercussions for a variety of syntactic phenomena.

Number may be viewed as an example of a deceptively simple and transparent nominal category. The common wisdom is that number straightforwardly expresses 
the ontological distinction between 'one' and 'more than one' object, a postulate based on the assumption that number is a nominal grammatical category. While this is undoubtedly true for a great number of languages, there are also languages that arguably have verbal number. Some of the most common examples are languages of the Austronesian family, which widely use verbal reduplication with a semantic effect of multiplying the number of events but not necessarily the number of event participants. Moreover, a semantic opposition expressed by number is not necessarily 'one' vs. 'more than one' (which corresponds to a familiar singular/plural distinction), as there are also languages with the dual for 'two', the trial for 'three' or the paucal for 'few'. In languages with nominal number, it is not necessarily expressed on each and every noun or nominal expression. There are languages where number is optional and languages where it is constrained to certain groups of nouns, count nouns in English being an example of such a constraint. Semantic contents of different values of number enter pragmatic interactions, allowing plurals to include singular referents and singulars to include pluralities. All those features make number far from a trivial property of nouns.

Number and gender are core features of nouns and make up or participate in some of the hallmark properties of natural language. The main goal of this volume is to contribute to their better understanding.

\section{The grammatical gender}

The term gender is highly polysemous, although in linguistics it usually has some well determined uses. On the one hand, it stands for the semantic information about biological sex and the corresponding cultural construct. This type can be called semantic (sometimes biological or natural) gender, where the relevant distinctions can be drawn between animate vs. inanimate, human vs. non-human, male vs. female and so on. Tamil (Dravidian family) is an example of a language with a semantic gender system: it has three gender classes, one is for gods and male humans, another one for goddesses and female humans and the third one for the rest (see Corbett 1991 and the references therein). In languages with semantic gender, the meaning of a noun automatically determines its gender, although some languages with semantic gender systems can exhibit various restrictions on and/or exceptions from this straightforward relation.

On the other hand, the term 'gender' is also used for a range of grammatical phenomena, including noun-classification into corresponding inflection classes and syntactically conditioned rules of agreement and concord. In the remainder of this section we will focus in more detail on this type of gender. Moreover, the same term 'gender' can also refer to presuppositions triggered about the former, semantic gender by the different instantiations of the latter, grammatical one. The polysemy of the linguistic term gender is not accidental - it stems from a tight relatedness between the phenomena it stands for.

In more general terms, various linguistic phenomena indicate that languages tend to follow one of the two strategies of noun classification (Dixon 1986): grammatical gender or nominal classifiers. Nominal classifiers typically match a 
semantic quantity property of the noun - thus subspecifying its interpretation and its behavior regarding number. The same noun may in principle combine with multiple classifiers, yielding different narrower interpretations, as illustrated in example (1) from Corbett (2007), where the noun iyá 'stone' receives three different denotations depending on the classifier it combines with.

$\begin{array}{llllll}\text { (1) iyá } & \text { Pa? } & \text { pe? } & \text { / kap } \\ \text { stone } & \begin{array}{l}\text { Cl.round } \\ \text { 'stone' }\end{array} & \begin{array}{l}\text { Cl.flat } \\ \text { 'digging stick' }\end{array} & \begin{array}{l}\text { Cl.together } \\ \text { 'gravel' }\end{array} & \text { Karo }\end{array}$

Grammatical gender is an alternative strategy, found in approximately half of the languages of the world (Corbett 1991; Audring 2016). Every noun in a grammatical gender language belongs to exactly one of a small and closed number of gender classes (possibly with few exceptional, so-called hybrid gender nouns). The classes are identified by a specific formal feature, which might be of a phonological or a morphological nature. An abstract example of the former type would be 'nouns ending in a vowel V are of gender X' (see an illustration from Spanish below), whereas morphological rules might require information about various morphological forms of a noun, for instance, its declension class or the declension class shown by its modifiers and predicates. Grammatical gender has a profound syntactic effect manifested in the way it determines asymmetric relations between constituents, namely, agreement.

There is a vast crosslinguistic variation concerning the interaction between grammatical and semantic gender. Typically (and unlike in classifier languages), grammatical gender classes can only be attributed some vague common semantic traits, which in a large number of languages, for animate nouns, include presuppositions related to the biological sex. Spanish, for instance, has two gender classes: feminine and masculine. The gender of a noun matters for the choice of the article you use with it, and for other grammatical phenomena, such as agreement with adjectives. For animate nouns the article choice is based on the biological sex: it is una/la mujer/madre/hermana 'a/the.FEM woman/mother/sister', but un/el hombre/ padre/hermano 'a/the.MASC man/father/brother'. For hybrid agreement nouns, i.e., animate nouns that keep the same form regardless of the biological sex of their referent, the article signals if the speaker is talking about a man or a woman: $l a$ violinista 'the.FEM violinist' (i.e., the female violinist) vs. el violinista 'the.MASC violinist' (i.e., the male violinist). For inanimate nouns, a number of rules mostly based on nominal endings are defined but no semantic basis has been identified for classifying inanimate nouns into two grammatical gender classes: nouns ending in - $o$ (and therefore resembling many animate nouns with male referents) are grammatically masculine, nouns ending in $-a$ (and therefore resembling many animate nouns with female referents) are grammatically feminine, i.e., el libro 'the.MASC book', but la fruta 'the.FEM fruit'. ${ }^{1}$

1. This is, of course, not the only rule of gender assignment in Spanish. The system is reasonably complex but is based on well-defined rules, so in general, it is quite 'well-behaved'. 
Another well-known group of languages with quite intricate grammatical gender systems, where, once again, biological sex largely determines the grammatical gender class for animate nouns, is the Slavic language family. Consider the illustration from Serbo-Croatian in (2).

(2)

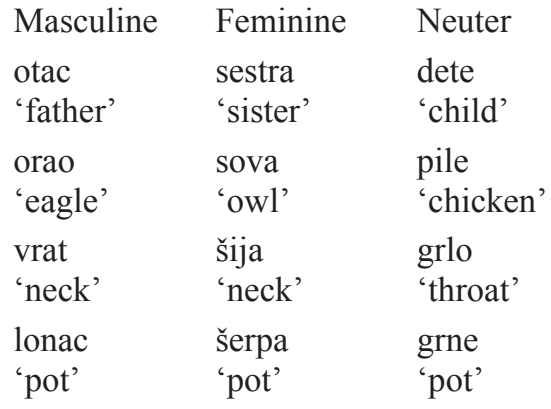

Serbo-Croatian

Serbo-Croatian, as a typical representative of the Slavic family, has three grammatical gender classes: masculine, feminine and neuter. For nouns referring to humans, the biological sex motivation for grammatical gender assignment is obvious: nouns denoting male humans are masculine, those denoting females are feminine and those whose denotations are culturally constructed as genderless are neuter. For animate but non-human denoting nouns, the sex of what is culturally established as the prototypical representative is reflected in the gender of the noun. Feminine ones like sova 'owl' involve a presupposition of female or unspecified sex, while masculine ones like orao 'eagle' come with a male or unspecified sex presupposition. In some cases, the cultural representation has males and females equally prominently represented, in which case they are referred to either by nouns involving different roots ( $k r a v a$ 'cow' vs. bik 'bull'), or both are derived by feminative and masculinative affixes from the same base ( $m a c ̌-k a$ 'she-cat', mač-or 'he-cat'). A curious restriction may be observed, testifying of the default status of the masculine gender: feminatives may be derived from morphologically simplex masculine animates, but masculinatives cannot be derived from feminine animates: slon (MASC) 'elephant' $\rightarrow$ slon-ica (FEM) 'she-elephant', riba (FEM) 'fish' $\rightarrow$ *rib-ac (MASC), intended: 'he-fish'. The question of animal gender is further discussed by Spathas \& Sudo (this volume) for Greek.

Inanimate nouns, however, seem to be assigned grammatical gender in an arbitrary way and hence it is very difficult to see a semantic foundation for the whole class of masculine, feminine or neuter gender nouns. Thus, considering that nouns of a particular grammatical gender involve semantic gender presuppositions only if they are animate, i.e. that for a majority of members no link can be established between the grammatical and semantic gender, the import of the component gender in the term grammatical gender is highly conditional.

As has already been mentioned above, grammatical gender manifests itself in two major ways. One is the morphological behavior of the noun - for instance, its declension class, as in Serbo-Croatian. Nouns from the same declension class (i.e. 
nouns taking the same set of case and/or number endings) are often referred to as same gender nouns. This is often at least partly supported by their semantic gender properties. For instance, the four Serbo-Croatian declension classes illustrated in (3) below are traditionally referred to as masculine, feminine in a consonant, neuter and feminine in - $a$, because they, respectively, only can include animate members if they denote male (or unspecified) individuals, female individuals, genderless (offspring) individuals, and female or male individuals.

\begin{tabular}{|c|c|c|c|c|c|c|c|}
\hline $\begin{array}{l}\text { Masc: } \\
\text { kralj, 'king' }\end{array}$ & Sg: & $\begin{array}{l}\text { Nom } \\
\text { kralj-Ø }\end{array}$ & $\begin{array}{l}\text { Gen } \\
\text { kralj-a }\end{array}$ & $\begin{array}{l}\text { Dat } \\
\text { kralj-u }\end{array}$ & $\begin{array}{l}\text { Acc } \\
\text { kralj-Ø }\end{array}$ & $\begin{array}{l}\text { Inst } \\
\text { kralj-om }\end{array}$ & $\begin{array}{l}\text { Loc } \\
\text { kralj-u }\end{array}$ \\
\hline $\begin{array}{l}\text { Fem in C: } \\
\text { peć, 'stove' }\end{array}$ & Sg: & $\begin{array}{l}\text { Nom } \\
\text { peć- } \varnothing\end{array}$ & $\begin{array}{l}\text { Gen } \\
\text { peć-i }\end{array}$ & $\begin{array}{l}\text { Dat } \\
\text { peć-i }\end{array}$ & $\begin{array}{l}\text { Acc } \\
\text { peć-Ø }\end{array}$ & $\begin{array}{l}\text { Inst } \\
\text { peć-ju }\end{array}$ & $\begin{array}{l}\text { Loc } \\
\text { peć-i }\end{array}$ \\
\hline $\begin{array}{l}\text { Neut: } \\
\text { nebo, 'sky' }\end{array}$ & Sg: & $\begin{array}{l}\text { Nom } \\
\text { neb-o }\end{array}$ & $\begin{array}{l}\text { Gen } \\
\text { neb-a }\end{array}$ & $\begin{array}{l}\text { Dat } \\
\text { neb-u }\end{array}$ & $\begin{array}{l}\text { Acc } \\
\text { neb-o }\end{array}$ & $\begin{array}{l}\text { Inst } \\
\text { neb-om }\end{array}$ & $\begin{array}{l}\text { Loc } \\
\text { neb-u }\end{array}$ \\
\hline $\begin{array}{l}\text { Fem in - } a \text { : } \\
\text { vila, 'fairy' } \\
\text { dasa, 'guy' }\end{array}$ & Sg: & $\begin{array}{l}\text { Nom } \\
\text { vil-a } \\
\text { das-a }\end{array}$ & $\begin{array}{l}\text { Gen } \\
\text { vil-e } \\
\text { das-e }\end{array}$ & $\begin{array}{l}\text { Dat } \\
\text { vil-i } \\
\text { das-i }\end{array}$ & $\begin{array}{l}\text { Acc } \\
\text { vil-u } \\
\text { das-u }\end{array}$ & $\begin{array}{l}\text { Inst } \\
\text { vil-om } \\
\text { das-om }\end{array}$ & $\begin{array}{l}\text { Loc } \\
\text { vil-i } \\
\text { das-i }\end{array}$ \\
\hline
\end{tabular}

The other manifestation of grammatical gender is the agreement that the noun controls on agreeing constituents. This manifestation of gender is less prone to ambivalence: only a very small number of nouns - known as epicene nouns, or hybrid agreement nouns (Corbett 1991) - trigger more than one agreement pattern. Consider the agreement patterns exemplified in (4):

\begin{tabular}{|c|c|c|c|c|}
\hline & \multicolumn{3}{|c|}{ Adj novi 'new' } \\
\hline & & Adj-Class Ø & Adj-Class -a & Adj-Class $-\mathrm{V}_{\text {mid }}^{2}$ \\
\hline Masc: & kralj, 'king' & $\underline{\text { nov-i kralj-Ø }}$ & *nov-a kralj-Ø & *nov-o kralj- $\varnothing$ \\
\hline Fem in $\mathrm{C}$ : & peć, 'stove' & *nov-i peć-Ø & $\underline{\text { nov-a peć- } \varnothing}$ & *nov-o peć-Ø \\
\hline Neut: & nebo, 'sky' & *nov-i neb-o & *nov-a neb-o & nov-o neb-o \\
\hline Fem in $-a$ : & $\begin{array}{l}\text { vila, 'fairy' } \\
\text { dasa, 'guy' }\end{array}$ & $\begin{array}{l}\text { *nov-i vil-a } \\
\text { nov-i das-a }\end{array}$ & $\frac{\text { nov-a vil-a }}{\text { *nov-a das-a }^{-}}$ & $\begin{array}{l}\text { *nov-o vil-a } \\
\text { *nov-o das-a }^{\text {nov }}\end{array}$ \\
\hline
\end{tabular}

Serbo-Croatian agreeing items, in particular adjectives, come in three agreement classes, as illustrated above, displaying, therefore, one declension class fewer than nouns, similarly to Romanian (as discussed in Corbett 1991). Besides the labeling of noun declension classes, another related phenomenon is also referred to by the term gender: the declension class of adjectives agreeing with the noun. Adjectival masculine declension class triggered in agreement is taken to indicate masculine gender of the noun irrespective of the declension class of the noun itself,

2. Similar to noun declension, adjectives have a class of endings including a zero ending in the nominative singular, one which has the ending $-a$ in this form, and one with a mid-vowel $(o / e)$, depending on the phonological properties of the stem. 
feminine declension class indicates feminine gender, neuter declension class neuter. This yields some terminological confusion, as for instance nouns of the feminine declension class in $a$ may be feminine or masculine when it comes to agreeing items. For this reason, descriptive names for declension classes (e.g. by their distinctive endings for a particular case-number combination) are terminologically superior to gender values, especially since the semantic gender imperfectly maps to both the declension class of the noun and that of the agreeing adjective.

The imperfect mapping can be observed in (4), where a specific declension class alone is sometimes not enough or does not matter for determining the agreement pattern, which is established on the basis of the semantic information (i.e., biological sex of a referent) conveyed by the noun. This is the case of dasa 'guy', which belongs to a 'feminine' declension class (see (3)), but exhibits, at the same time, a 'masculine' agreement pattern (see (4)). The main idea is that there is a strong, though still imperfect, dependency between the agreement displayed and the cultural gender, i.e. the biological sex of the referent.

This description of Serbo-Croatian nominal gender outlines a multilayered system, with complex relations and dependencies between noun-classification and its semantic base (including, but not limited to the semantic gender), the inflection class of the noun, and the inflection class of the agreeing items. Questions emerge regarding the status of the grammatical gender, from its formal properties to its interpretive effects.

Traditionally, grammatical gender has been seen as an immanent property of a noun (Corbett 2007). Researchers have been investigating nominal gender, noun classification and related notions of noun declension or noun agreement classes. Thus, a noun has always been viewed as a locus of grammatical gender information. Yet recent formal approaches have decomposed nouns into gender-neutral bases (roots or words of other lexical categories) and category and inflection class related information (of the noun itself and of the agreeing items) stemming from functional features in the structural shell through which the noun is derived (Borer 2005; Kramer 2015; Arsenijević 2018). This yields the question of what the locus of grammatical gender is, and what the relation is between the lexical noun (or its base, be it a root or a word) and the functional features in its structural environment deriving the morphosyntactic noun.

There is a variety of proposals in the literature regarding syntactic representation of grammatical gender. The majority converge on the idea that gender should be modelled via features (interpretable or uninterpretable), which helps to account for the fact that nominal gender actively participates in agreement relations. The proposals differ, however, with respect to a precise location of this gender feature in the syntactic structure. It seems that postulating a Gen(der)P, as suggested, for instance, by Picallo (1991) or Koopman (2003) is not a particularly fruitful way to implement gender information into syntax, as has been argued by Alexiadou (2004), Kramer (2015), etc. One of the main reasons for rejecting a specific projection for gender information is that there seems to be no uniform semantics that could be attributed to this projection, but there are also other, more specific reasons, some of which put forward and discussed by Kramer (2015). 
It might appear that gender information could be encoded in a syntactic projection associated with number (e.g, NumP), as sometimes number and gender show intricate dependencies (Ritter 1993). For instance, in Romanian and SerboCroatian, there is a large class of nouns that show masculine agreement in singular and feminine in plural, which is different from both 'pure' masculine and feminine nouns which always follow a masculine or a feminine agreement pattern (Corbett 1991). Despite the fact that there is little compelling evidence for base-generating gender information in the NumP (cf. Acquaviva 2008; Kramer 2015), there is a broad range of cross-linguistic data showing that the two categories closely interact and/or even converge in some cases, as discussed in Fassi Fehri (this volume). The structural relation between number and gender should be modelled taking these facts into account, and one possible way of capturing this interaction is by postulating two number projections one of which also holds gender information, as proposed in Manzini (this volume).

The most widespread view in the gender literature locates gender features on the noun (e.g., Harris 1991; Wechsler \& Zlatic 2003; Alexiadou 2004), at the very bottom of the nominal functional projection. This brings us back to a traditional view that we started with, although decompositional syntactic theories give a little twist to the traditional story. Decomposition-based variants of this view (Borer 2005; Acquaviva 2009, this volume; Kramer 2015), as mentioned above, argue that gender features are not located on the root, which is assumed to lack any grammatical features, but rather on (or around) the category-defining head $n$, which also makes it easier to explain that gender plays a role in other grammatical phenomena in different languages, which include nominalizations, declension classes, relation to number and pervasive agreement effects.

Finally, it should also be mentioned that some approaches advocate multiple locations for gender features (see Yatsushiro \& Sauerland 2006; Steriopolo \& Wiltschko 2010; Pesetsky 2013), typically distinguishing between grammatical and semantic gender (cf. Spathas \& Sudo, this volume), which can also account for mixed agreement patterns with hybrid agreement nouns.

The question of the locus of gender information is related to the more general question of the nature of the semantic gender and its relation with the grammatical gender. For languages with semantic gender systems, like Tamil, briefly mentioned above, the question arises as to where and how this semantic information is coded: in the lexical meaning of the noun, in the formal specification of its declension class, or is it pragmatically construed based on purely formal morphological and syntactic information (see e.g. Sauerland 2008)? GenP, also discussed above, would probably be a candidate, except that there is little cross-linguistic evidence for universally projecting such a phrase. Actually, cross-linguistic data pose yet another semantic challenge, namely, how to reconcile purely semantically based gender systems like the one found in Tamil with less straightforward (from a semantic viewpoint) systems found in languages like Spanish or Serbo-Croatian, where semantic gender overlaps with (and in certain cases overrules) grammatical gender. Moreover, semantic interpretation of gender features varies greatly among languages and it is difficult to capture this variation in a coherent, well-motivated 
and non-stipulative way. An additional complication is (what seems to be) an arbitrary gender assignment to inanimate nouns in languages with grammatical gender systems: 'table' is masculine in Russian (stol) and feminine in Spanish (mesa), but it is far from obvious what this gender information tells us about the lexical item 'table', if anything at all.

As values of grammatical features often form hierarchies of markedness, another important research field is formed around the question of what is the markedness hierarchy of the values of grammatical gender across the various dimension of markedness (frequency, semantic restrictedness, morphophonological complexity, processing complexity), whether these hierarchies are universal or prone to variation, and what relations can be observed between different dimensions of markedness.

One of the values of grammatical gender is typically morphophonologically the lightest, the most frequent in occurrence and therefore also the simplest to grammatically process. Consider the Serbo-Croatian masculine nouns in (5) and adjectives in (6), where the masculine form with a zero ending is morphophonologically lighter than neuter and feminine. Feminine nouns in a consonant also have a zero ending in the nominative (cf. (5d)), but this declension class is limited to the noun-declension system that is absent from the adjectival declension, which testifies of its markedness along the morphological dimension.

a. zid- $\varnothing$

wall.MASC

(6) b. zvon-o

bell.NEUT

b. mlad-o young.NEUT c. sob-a

room.FEM-V

c. mlad-a young.FEM-V d. noć- $\varnothing$

night.FEM-C

A common indicator of (un)markedness is frequency. For Serbo-Croatian, among the 5000 most frequent nouns in the srWaC corpus $(<\mathrm{http}: / / \mathrm{nlp}$.ffzg.hr/ resources/corpora/srwac/>), 2390 are masculine (over 54 million tokens), 1566 are feminine in - $a$ (nearly 40 million tokens), 729 are neuter (around 14 million tokens) and 176 are feminine in a consonant (just over 4 million tokens), which further confirms the unmarked status of the masculine, as well as the marked status of the feminine nouns in a consonant, with the remaining two classes somewhere in between.

From the semantic point of view, considering familiar languages where the grammatical masculine is the default and the feminine is marked, most researchers tend to analyze the grammatical feminine gender on animates as involving a female presupposition and the grammatical masculine gender as actually semantically underspecified (Sauerland 2008; Percus 2011, a.o.). Rather than involving a male presupposition, the masculine grammatical gender only presupposes semantic gender, with an affinity for male interpretation stemming from antipresupposition. Sudo \& Spathas (2019, this volume) argue that male presupposition, and even assertion, may as well be contributed by nouns. However, even on their account, this is not an effect of their grammatical gender itself, but rather of its interaction with other available nouns. 
In the simplest case, morphophonological, semantic and frequential hierarchy of markedness of gender classes match. However, mismatches emerge in all combinations, like the one above between the morphophonological simplicity and frequential scarcity of feminine nouns in a consonant in Serbo-Croatian. Such cases present valuable windows into the nature of gender systems.

Noun classification, especially in its association with count-classifiers (Corbett 2007; Krifka 1989; Cheng \& Sybesma 1999), establishes a close link with the properties of quantity, such as atomicity, countability, the specification of the unit of counting (Krifka 1989; Landman 2011; Chierchia 1998). As grammatical gender has been argued to realize the same underlying phenomenon (Corbett 2007; Dixon 1986), one wonders to what extent grammatical gender is linked with the properties of quantity of the predicate denoted by the noun (Hachem 2015; Fassi Fehri 2018, this volume; Arsenijević 2018).

This last area of investigation of grammatical gender directly links to the other core grammatical feature of the noun: the grammatical number.

\section{The grammatical number}

Grammatical number is one of the nominal categories that appear simple and straightforward but nevertheless present difficult challenges both from a descriptive and from a theoretical viewpoint. Like grammatical gender, grammatical number can be realized through inflection on the noun and/or through the agreement that it triggers on other items. However, unlike grammatical gender, grammatical number has stable, straightforward and systematic interpretive effects, related to the quantity of the predicate denoted by the noun, and hence also of the referent when the nominal expression is referential.

In the typological perspective, there is a range of meanings associated with the grammatical category of number. They include: minimal, singular, augmented, dual, trial, unit-augmented, plural, greater plural, and global plural. ${ }^{3}$ For each of these meanings there are a number of languages in which they receive morphosyntactic marking, i.e., where they match formal values of grammatical number. Yet no language displays all of them. Normally, a language has two or three different values of grammatical number, matching a subset of the listed meanings, but there are also languages with four or five values of grammatical number (cf. Corbett 2000). For illustration, consider the five number values marked on the third person pronoun in Lihir, an Austronesian language (Corbett 2000: 25):
(7)
dul
dietol
diehet
die
'he' 'the two of them'
'the three of them'
the few of them'
'they'

3. All these terms already contain a vague description of the respective meanings. A more precise characterization of all the number values are beyond the goals of this introduction; the reader is referred to Greenberg (1966), Corbett (2000), Harbour (2007) for a more detailed discussion. 
One of the principal questions concerning the grammatical number is whether the semantic contribution of a value of number can be independently specified or its meaning universally emerges in interaction with other values. For some of the values we can be sure that the latter is the case. Greater and global plural are always interpreted relative to the meaning of the plural, and unit-augmented is a specific type of augmented. It is hence not a surprise that in such cases no language may have the narrower value without the more basic one, i.e. there is no language with a greater plural that does not have plural. Values without an obvious interpretive dependency from other values also enter implicational relations. For instance, no language has a trial that does not have a dual, as well and no language has the dual without having both the singular and the plural (Greenberg 1966). These dependencies, to which we refer as implicational universals, support the view in which values of number are universally interpreted relative to each other.

Semantic imports of the values of grammatical number may further be exact, in the sense that their meaning involves a specific cardinality, such as the singular, dual, trial, or unit-augmented, or they may be approximative, such as the paucal, which stands for a small count quantity, or the greater plural, corresponding to an excessive quantity. The regular plural does not fall in either of the classes, as it is fully independent of cardinality and captures any quantity - with a possible exception of singularity. Approximative values may further be divided into those with an upper (the paucal) and those with a lower bound (the greater plural). How a value of grammatical number interacts with the context depends on its semantic strength, i.e. its semantic markedness - which is another important factor in the implicational universals that relate them. This obviously calls for a unified theory of the different dimensions of markedness, not only regarding the plural and the singular, but regarding all the possible number values.

Harbour (2014) presents a formal theory of number that aims at modelling the typological diversity of number realizations via a set of features. Syntactically, Harbour (2014: 191) assumes the following minimal structure for nominal phrases:

$$
\left[{ }_{\text {NumberP }} \text { Number }\left[{ }_{n \mathrm{P}} \mathrm{n} \text { Vroot }\right]\right]
$$

The Number head hosts a bunch of number-related features, namely, [ \pm additive $],[ \pm$ minimal $]$ and $[ \pm$ atomic $]$, whose possible combinatorial variants define typologically diverse number systems in various languages. Not all of the features are necessarily present in all languages or even for all nouns in one particular language. Different (recursive) combinations of features and feature values are language specific. In English, for instance, only the [ \pm atomic] feature is present, whereas in languages like Walpiri, which has a singular-dual-plural system, $[ \pm$ minimal $]$ and $[ \pm$ atomic $]$ features are realized. Approximative number in Harbour's theory is represented via the feature [ \pm additive]: languages that have this feature in the number inventory also have (some of the) approximative number values, i.e., paucal, greater plural or global plural. Martí (this volume) tests the predictions of the feature system for languages that mark paucal, in addition to singular and plural. 
Number distinctions can, but do not necessarily have to be morphologically expressed in a language. If in English the speakers are forced to make a choice between a singular and a plural form for every count noun used in speech, for some languages the expression of number is optional. Many languages employ a so-called 'general' number form (Corbett 2000), which is interpreted as underspecified with respect to the number of referents (can be one or several, or many) and is used when the number information is irrelevant. General number can be morphologically distinct from other number forms (e.g., in Bayso, a Cushitic language) or coincide with some other form, for instance, with the singular (e.g., in Japanese). Consider an example from Bayso (Corbett 2000: 11):
a. lúban
foofe
lion.GENERAL watched.1SG
literally: 'I watched lion' (it could be one, or more than that)
b. lubán-titi foofe
lion.SG watched.1SG
'I watched a lion.'
lion.PAUCAL watched.1SG
'I watched a few lions.'
c. luban-jaa foofe
d. luban-jool foofe
lion.PL watched.1SG
'I watched (a lot of) lions.'

Morphosyntactically, grammatical number is often fused with grammatical gender (expressed by a single morpheme). Both its morphosyntactic and semantic properties suggest that to the extent that it has a separate realization, it sits higher than gender. Availability of suppletive forms for number in a wide range of languages suggest, however, that it is realized very close to the noun. For this reason, it is typically modelled immediately dominating the projection hosting gender. Both theoretical and experimental work indicate, however, that the two features are represented separately, and enter syntactic operations separate from each other - although with a strong interaction (Fuchs et al. 2015; Mitić \& Arsenijević 2019).

The semantics of number signals a higher degree of complexity than traditionally assumed. Even languages where number expression is generally obligatory, like English or Spanish, have nominal forms that do not necessarily specify quantitative information. In languages with articles and obligatory number marking on nouns, bare (i.e., article-less) forms do not always express the corresponding quantity. Bare singulars in Spanish can be used in certain contexts with the meaning 'one or more than one':

(10) Tengo coche.

have.1SG car

Lit: 'I have car.' (I am a car-owner; I have one or more cars in my possession) 
This phenomenon, usually called 'number neutrality', has been shown to exist in quite a few languages, for instance West Greenlandic (van Geenhoven 1998), Hungarian (Farkas \& de Swart 2003), Hindi (Dayal 2011), Catalan and Spanish (Espinal \& McNally 2011), Norwegian (Borthen 2003), Brazilian Portuguese (Dobrovie-Sorin \& Pires de Oliveira 2008) and is a hallmark of some grammatical processes like pseudo-incorporation (cf. Borik \& Gehrke 2015).

Furthermore, both singular and plural forms in their 'canonical' uses can exhibit unusual interpretive effects, at least under the basic assumption that the term singular means 'one' and plural - 'more than one'. Plural can include singleton referents and, on some views at least, singular can include pluralities in its denotation (see e.g. Sauerland et al. 2005). Examples (11a-b) typically mean that someone with five children will also get the additional days off, and if the hearer sees ten free chairs, they should let the speaker know. Similarly, in (11c-d), if the hearer has one child, she is free to bring her, and if there is one single chair available, the sentence is false, respectively.

(11) a. Everyone who has a child gets 2 additional days off.

b. If you see a chair, let me know.

c. You're welcome to bring your children.

d. No chairs are available.

That the quantity interpretation of singulars and plurals depends on the logical properties of the linguistic context has been accepted by most researchers in the field. Yet what the narrow meanings of the values of grammatical number are, and how the dependencies are to be modelled remains under debate (Hoeksema 1983; van Eijck 1983; Schwarzschild 1996; Chierchia 1998; Sauerland et al. 2005; Farkas \& de Swart 2010).

Grammatical number also interacts with other dimensions of nominal semantics. Both plurals and singulars can have a generic interpretation, ${ }^{4}$ although in the literature on genericity these denotations have been argued to display important differences (Chierchia 1998; Doron 2003; Dayal 2004). Bare plurals in English have been in the spotlight of attention in formal semantics at least since Carlson (1977/1980), a seminal work on generic reference. Carlson's hypothesis is that bare plurals in English uniformly refer to kinds, as in (12a), not to individuals, as in (12b). An existential interpretation of a bare plural nominal phrase in (12b) is possible only in certain contexts, when a (stage-level) predicate combines with the realization(s) of the kind.

(12) a. Lions are predators.

b. Lions are lying on the lawn.

4. Other values of number, apart from the global plural, cannot receive generic interpretation. 
This line of analysis is taken up by Chierchia (1988) and Dayal (2004), although Krifka (2004) argues for an ambiguity-based analysis of bare plurals with independent semantic mechanisms that derive generic and existential interpretations.

Singular definite generics (i.e., the lion) have been enjoying less attention, probably due to the fact that their distribution is more restricted in comparison with bare plurals (cf. a well-established kind restriction, Krifka et al. 1995). However, Dayal's (2004) analysis of kinds is extended to cover both singular and plural expressions with a generic reference. Moreover, in her account grammatical number plays a crucial role in kind interpretation. Kind reference, according to Dayal, is based on conceptual and semantic plurality, thus, for English the default way to refer to kinds is by means of bare plurals. Singular morphology coerces an underlyingly plural kind interpretation into a taxonomic one, giving rise to a definite kind expression like the lion. Borik \& Espinal (2015, this volume) defend an alternative view based on the data from Spanish and Russian: what appears to be a singular kind expression is, in fact, an expression without number. Their account relies on conceptualizing number as a realization operator (cf. Déprez 2005; Espinal \& McNally 2007), similar, but not identical to Carlson's realization operator.

A kin concept to quantity, which is assumed to underlie the meaning of grammatical number, is counting, which can be expressed in different ways in a language, one of the most common means being numerals. In some languages, the connection between numerals and grammatical number is more obvious than in others. In English, Russian and Spanish numerals (one vs. the rest) seem to determine the number morphology of the complement noun: one combines with singular nouns, all numerals greater than one require plural number morphology. In Turkish or Hungarian the number morphology is uniformly singular, independently of the numeral. Various accounts exist that aim to explain this variation (see Ionin and Matushansky 2006, 2018; Farkas \& de Swart 2014; Scontras 2014; Martí 2020), focusing on both syntax and semantics of cardinal numerals. However, the full scale of the typological variation in this construction needs to be explored much further and in much more detail. The typological variation in the form and meaning of the numerals themselves is also widely discussed in the literature (cf. Rothstein 2017; Wągiel \& Caha, this volume).

\section{The collection}

Each of the papers in this volume tackles one or several of the core issues outlined in sections 2-3, and further expands the range of research questions and target phenomena.

In their paper Gender on animal nouns in Greek, Spathas and Sudo discuss animal nouns in Modern Greek, which appear to contradict the established generalization that masculine is the unmarked semantic (i.e. natural) gender in Greek. Greek animal nouns turn out to allow all three genders to act as the semantically unmarked values, depending on the particular noun. The authors argue that animal nouns behave differently from human-denoting nouns. They attribute the unmarked behavior observed in the former to the grammatical gender of the nouns, with the 
effects on semantic gender being indirect. They consider the consequences of their analysis for the syntactic representation of gender, favoring a view in which semantic gender figures as a syntactic feature independent of the grammatical gender, and where these two features are represented in different functional projections. In order to maintain that asserted gender universally comes from lexical semantics, hence from the level of roots, they propose that suffixes which are associated with the effect of gender assertion (i.e. suffixes which derive specific semantic gender nouns) form new roots with the roots they attach to.

Gender as a property of nouns and as a property of structures by Paolo Acquaviva provides a series of arguments that the formal feature of grammatical gender does not stem from the lexical representation of the noun, but rather resides in the syntactic structure which embeds it. The author focuses on several main observations. One is a contrast between what he calls alliterative concord - the situation where the items agreeing with a noun in gender simply copy its inflection ending - and different types of cases in which no match occurs. The latter situation occurs because the agreeing category has a different set of declension classes, because it undergoes a special mapping to the noun-declension classes, or because it picks a non-matching declension class. He further points nouns forming minimal pairs regarding grammatical gender and its semantic effects, where both nouns are morphologically marked. Similar is the situation with Italian personal pronouns. These facts are argued to show that the semantic contribution of the grammatical gender regarding the natural, i.e. biological gender crucially requires the functional feature [animate] in a particular structural relation as a trigger. These arguments are then related to the question of the ontological status of the grammatical gender, where it is argued that it is fully dissociated from semantic or phonological content, and that its deep nature lies in its structural role of bearing agreement.

Abdelkader Fassi Fehri, in his paper titled Number and gender convergence: The Arabic plurative, places grammatical gender and number along the same dimension, in an approach that unifies their syntax and semantics. The target of the paper is a particular construction in Arabic which unifies the semantics of singular and plural - much in the way of the traditional collective nouns. The author terms this construction the plurative, thus putting it in a minimal pair with its inverse: the singulative. Somewhat informally speaking, the paper models the semantics of the plurative as a 'whole sum' in which atoms lack the status of separate objects. It is crucially shown that in these constructions, the properties of quantity are not contributed by grammatical number, but by grammatical gender. This fits well in the general claim that grammatical gender establishes the basic properties of quantity that grammatical number operates on. A general theoretical consequence at the level of syntax is drawn, that the properties of quantity standardly modeled in terms of a single projection, termed the division, or classifier phrase (DivP / ClP) require minimally two distinct projections to be properly captured. One of them, labeled atomP, is in charge for the atomic structure (whether the predicate derived is characterized by atomicity or not, potentially including a restriction of the atomic unit). The other, unitP, operates on the output of the atomP specifying the part-whole perspective by generating a lattice or specifying a referential unity. 
A closely related set of phenomena, and with closely related syntactic theoretical implications, is analyzed in the paper The morphosyntactic structure of number in Romance and Albanian. High and low plurals authored by Maria Rita Manzini. The paper departs from a typological taxonomy of grammatical number systems based on Semitic languages, which classifies languages into those with high plurals sitting in the dedicated NumP projection, low ones marked on the categorical head (associated with the gender, i.e. noun-classification) and languages with both types of plurals. Applying the taxonomy to Italian dialects and Albanian, the author observes that all three types are manifested among the target varieties. The paper offers a formal model of the facts, using three different flavors of divisiveness available for the classifier projection, one of which derives mass, another plural semantics, and the third encompassing both these meanings. As this projection is related to gender, the author offers a discussion and proposes a formalization of the gender-quantity semantics mapping and interactions, effectively converging on the view that gender and number both play an essential role in the derivation of number semantics and marking. The proposed analysis is tested against the background of Semitic languages for which the typology of number was originally proposed.

Luisa Martí in her paper Dual Number and the Typology of the Numeral-Noun Construction focuses on the morphology and semantics of a numeral + noun construction with a special attention to languages that, in addition to singular and plural, also mark dual as a separate value in their number system. The theoretical proposal advocated in the paper rests on the theory of number features developed by Harbour (2014) and the nominal phrase architecture proposed by Scontras (2014), which includes NumberP and NumeralP projections in the structural representation of nominals. The author first demonstrates how her theory accounts for the numeral + noun combination in languages like English, which only exhibits a singular vs. plural contrast, and then proceeds to check out the predictions of the feature-based system for languages that also have a dual number form. Crucially, she argues that to account for languages with dual number, the order of the NumberP and NumeralP could be reversed. Empirically, some predictions of the proposal developed by Martí are confirmed by languages with dual number (Yimas, Hopi), although one of the predicted patterns still awaits empirical support. Two languages that appear to present some problems for the proposal include Ljubljana Slovenian and Imere, although the author argues that those problems can be successfully accounted for.

Another paper that examines the properties of numerals is Universal Semantic Features and the Typology of Cardinal Numerals by Marcin Waggiel and Pavel Caha. In their analysis of the observed variation in the form and meaning of cardinal numerals, the authors depart from a fundamental observation that there are two functions that cardinal numerals perform: abstract counting (i.e., denoting a number concept) and object counting (i.e., quantification over individuals). Abstract counting is assumed to be a basic function and it is argued that object counting numerals both syntactically and semantically contain abstract counting numerals. Even though morpho-lexical relations between two types of numerals can vary (the numerals can have the same form, one form can be morphologically more complex, two forms can be morphologically unrelated), they are argued to be uniform in their 
structural representation and include a combination of three syntactic heads: SCALE, Num (for 'number') and CL (for 'classifier'). The structure postulated for abstract counting numerals is less complex and does not include a CL head, which forms part of the structure associated with object counting numerals. In those languages where a $C_{L}$ head is pronounced on the numeral, it is chosen in accordance with the morphological or semantic class of the noun modified by the numeral and is akin to gender.

Finally, Olga Borik and M. Teresa Espinal in their contribution entitled Numberless kinds: evidence from Russian examine the role of number in the expression of genericity. Empirically, they part from the well-known fact that both morphologically singular and plural nominal phrases can be used with a generic reference, but they argue that, from a theoretical viewpoint, a generic expression that is morphologically singular should be structurally represented as numberless. The claim was made in their earlier work for Spanish, but in the contribution to this volume the authors argue that the claim also finds empirical support in Russian. Russian generic nominals that appear in a morphologically singular form cannot be combined with numerals or with any other determiners or quantifiers, the fact that, as Borik and Espinal point out, follows more naturally from the analysis that does not postulate number in the representation of this kind of expressions. Theoretically, their analysis of number is based on a view that both originates and finds a lot of empirical support in the literature on bare nominals (cf. Déprez 2005; Espinal \& McNally 2011, etc.): number is defined as a realization operator that applies to properties of kinds and yields properties of objects. The paper presents a formal analysis of number and explains empirical differences between 'proper' singulars, which are object referring, and numberless kinds, which, according to the hypothesis, are numberless.

The papers that compose this volume deal with some intriguing and thoughtprovoking research questions concerning the nature of gender and number in the nominal domain, possible theoretical approaches to model their contribution to the syntax and semantics of nominals, and the relations of number and gender among each other and with other nominal categories. We find the issues raised in the volume truly fascinating, and hope that the reader will agree with us after having read the contributions themselves.

\section{References}

Acquaviva, P. 2008. Lexical Plurals. Oxford: Oxford University Press.

Acquaviva, P. 2009. Roots and lexicality in Distributed Morphology. In A. Galani, D. Redinger \& N. Yeo (eds.). York- Essex Morphology Meeting 5: Special Issue of York Working Papers in Linguistics, 1-21. York: University of York.

Alexiadou, A. 2004. Inflection class, gender and DP-internal structure. In G. Müller, L. Gunkel \& G. Zifonun (eds.). Explorations in Nominal Inflection, 21-50. Berlin: Mouton.

Arsenijević, B. 2018. Gender, like classifiers, specifies the type of partition: Evidence from Serbo-Croatian. Proceedings from the Annual Meeting of the Chicago Linguistic Society 52(1): 21-37. 
Arsenijević, B. 2020. Adjectives as a lexical category - a story of striving for extension. To appear in: M. Mitrović \& P. Panagiotidis (eds.). $A^{\circ}$ : The Lexical Status of Adjectives. Amsterdam: Jon Benjamins.

Mitić, I. \& Arsenijević, B. 2019. Plural conjuncts and syncretism facilitate gender agreement in Serbo-Croatian: experimental evidence. Frontiers in Psychology 10(942): 1-14.

Borer, H. 2005. Structuring Sense, Vol. 1: In name only. Oxford: Oxford University Press.

Borik, O. \& Gehrke, B. 2015. An introduction to the syntax and semantics of pseudo-incorporation. In O. Borik \& B. Gehrke (eds.). The Syntax and Semantics of Pseudo-Incorporation, 1-43. Leiden: Brill.

Borik, O. \& Espinal, M.T. 2015. Reference to kinds and to other generic expressions in Spanish: definiteness and number. The Linguistic Review 32(2): 167-225.

Borthen K. 2003. Norwegian Bare Singulars. Ph.D. Dissertation. Norwegian University of Science and Technology.

Carlson, G. 1977/1980. References to kinds in English. PhD dissertation, University of Massachusetts at Amherst. Published by Garland, New York 1980.

Cheng, L. \& Sybesma. R. 1999. Bare and Not-So-Bare Nouns and the Structure of NP. Linguistic Inquiry 30: 509-542.

Chierchia, G. 1998. Reference to Kinds across Languages. Natural Language Semantics 6: 339- 405.

Corbett, G.G. 1991. Gender. Cambridge: Cambridge University Press.

Corbett, G.G. 2000. Number. Cambridge: Cambridge University Press.

Corbett, G.G. 2007. Gender and Noun Classes. In T. Shopen (ed.). Language Typology and Syntactic Description, 2nd ed., 241-279. Cambridge: Cambridge University Press.

Dayal, V. 2004. Number marking and indefiniteness in kind terms. Linguistics and Philosophy 27: 393-450.

Dayal, V. 2011. Pseudo incorporation in Hindi. Natural Language and Linguistic Theory, 29: 123-167.

Déprez, V. 2005. Morphological number, semantic number and bare nouns. Lingua, 115: 857-883.

Dixon, R.M.W. 1986. Noun classes and noun classification in typological perspective. In C. Craig (ed.). Noun classes and categorization: Proceedings of a symposium on categorization and noun classification, Eugene, Oregon, October 1983, 105-112. Amsterdam: John Benjamins.

Doron, E. 2003. Bare singular reference to kinds. Proceedings of SALT 13: 73-90. Seattle: University of Washington. In R. B. Young and Y. Zhou (eds.). Proceedings of Semantics and Linguistics Theory XIII, Seattle: University of Washington, 73-90.

Dobrovie-Sorin, C. \& Pires de Oliveira, R. 2007. Reference to Kinds in Brazilian Portuguese: Bare Singulars vs. Definite Singulars. In Grønn, A. (ed.). Proceedings of SuB12, 107-121. Oslo: ILOS 2008 (ISBN 978-82-92800-00-3).

Espinal, M.T. \& McNally, L. 2007. Bare singular nominals and incorporating verbs. In G. Kaiser \& M. Leonetti (eds.). Definiteness, specificity and animacy in IberoRomance languages, 45-62. Arbeitspapier 122, University of Konstanz.

Espinal, M. T. \& McNally, L. 2011. Bare nominals and incorporating verbs in Catalan and Spanish. Journal of Linguistics 47: 87-128. 
Farkas, D. \& de Swart, H. 2003. The Semantics of Incorporation. Stanford: CSLI Publications.

Farkas, D. \& de Swart, H. 2010. The semantics and pragmatics of plurals. Semantics and Pragmatics 3: 1-54.

Fassi Fehri, A. 2018. Constructing the feminine to mean. Gender, number, numeral, and quantifier extensions in Arabic. New York: Lexington Books.

Fedden, S. \& Corbett G.G. 2017. Gender and classifiers in concurrent systems: Refining the typology of nominal classification. Glossa: A Journal of General Linguistics 2(1): 1-47.

Fuchs, Z., Polinsky, M. \& Scontras, G. 2015. The differential representation of number and gender in Spanish. Linguistic Review 32: 703-737.

Van Geenhoven, V. 1998. Semantic Incorporation and Indefinite Descriptions: Semantic and Syntactic Aspects of West Greenlandic Noun Incorporation. Stanford: CSLI Publications.

Greenberg, J. H. 1966. Some universals of grammar with particular reference to the order of meaningful elements. In J. H. Greenberg (ed.). Universals of language, 73-113. Cambridge, Massachusets, and London, England: MIT Press.

Hachem, M. 2015. Multifunctionality. The internal and external syntax of D-and W-Items in German and Dutch. Utrecht: LOT-Publication.

Harbour, D. 2007. Morphosemantic Number: From Kiowa Noun Classes to UG Number Features. Dordrecht: Springer.

Harbour, D. 2014. Paucity, Abundance and the Theory of Number. Language 90(1): 185-229.

Harris, J. 1991. The exponence of gender in Spanish. Linguistic Inquiry 22: 27-62.

Hockett, C. F. 1958. A course in modern linguistics. New York: Holt/Rinehart and Winston.

Hudson, R. 1994. About 37\% of Word-Tokens are Nouns. Language 70(2): 331-339.

Ionin, T. \& Matushansky, O. 2006. The composition of complex cardinals. Journal of Semantics 23: 315-360.

Ionin, T. \& Matushansky, O. 2018. Cardinals. The Syntax and Semantics of CardinalContaining Expressions. Cambridge MA: The MIT Press.

Koopman, H. 2003. The locality of agreement and the structure of the DP in Maasai. In W.E. Griffin (ed.). The Role of Agreement in Natural Language: TLS 5 Proceedings, 207-227.

Kramer, R. 2015. The Morphosyntax of gender. Oxford: Oxford University Press.

Krifka, M. 1989. Nominal reference, temporal constitution and quantification in event semantics. In R. Bartsch, J. Van Benthem \& P. Van Emde Boas (eds.). Semantics and Contextual Expressions, 75-115. Dordrecht: Foris.

Krifka, M. 2004. Bare NPs: Kind-referring, Indefinites, Both, or Neither? In O. Bonami \& P. C. Hofherr (eds.). Empirical Issues in Formal Syntax and Semantics, 5: 111-132.

Krifka, M., Pelletier, F. J., Carlson, G., Ter Meulen, A., Chierchia, G. \& Link, G. 1995. Introduction. In G. Carlson, F. J. Pelletier (eds.). The Generic Book, 1-124. Chicago: The University of Chicago Press.

Landman, F. 2011. Count Nouns - Mass Nouns, Neat Nouns - Mess Nouns. The Baltic International Yearbook of Cognition, Logic and Communication 6: 1-67.

Martí, L. 2020. Numerals and the theory of number. Semantics and Pragmatics 13(3). $<$ https://doi.org/10.3765/sp.13.3> 
Moravcsik, E. A. 1975. Verb borrowing. Wiener Linguistische Gazette 8: 3-30.

Percus, O. 2011. Gender features and interpretation: a case study. Morphology 21(2): 167-196.

Pesetsky, D. 2013. Russian Case Morphology and the Syntactic Categories. Cambridge, MA: MIT Press.

Picallo, M. C. 1991. Nominals and nominalization in Catalan. Probus 3: 279-316.

Ritter, E. 1993. Where's gender? Linguistic Inquiry 24: 795-803.

Rothstein, S. 2017. Semantics for Counting and Measuring. Cambridge: Cambridge University Press.

Sasse, H. J. 2001. Scales between nouniness and verbiness. In M. Haspelmath, E. König, W. Oesterreicher \& W. Raible (eds.). Language typology and language universals, (HSK 20), 495-509. Berlin: De Gruyter.

Sauerland, U., Anderssen J. \& Yatsushiro K. 2005. The plural is semantically unmarked. In S. Kepser \& M. Reis (eds.). Linguistic Evidence - Empirical, Theoretical, and Computational Perspectives, 413-434. Berlin, Germany: Mouton de Gruyter.

Sauerland, U. 2008. On the semantic markedness of phi-features. In D. Harbour, D. Adger \& S. Béjar (eds.). Phi Theory: Phi-Features across Modules and Interfaces, 57-82. Oxford: Oxford University Press.

Scontras, G. 2014. The Semantics of Measurement. PhD dissertation, Harvard University.

Steriopolo, O. \& Wiltschko, M. 2010. Distributed GENDER hypothesis. In G. Zybatow et al. (eds). Formal Studies in Slavic Linguistics: Proceedings of the Formal Description of Slavic Languages 7.5, 155-172. New York: Peter Lang.

Sudo, Y. \& Spathas, G. 2019. Natural Gender and Interpretation in Greek: Comments on Merchant (2014). Ms., UCL, L-ZAS.

Wechsler, S. \& Zlatic, L. 2000. A theory of agreement and its application to SerboCroatian. Language 76: 799-832.

Yatsushiro, K. \& Sauerland, U. 2006. [Feminine] in a high position. Snippets 13: 11-12. 